\title{
Population modelling of European shags (Phalacrocorax aristotelis) at their southern limit: conservation implications
}

\author{
Alberto Velando ${ }^{\mathrm{a}, *}$, Juan Freire ${ }^{\mathrm{b}}$ \\ ${ }^{a}$ Departamento de Ecoloxía e Bioloxía Animal, Universidade de Vigo, 36200 Vigo, Spain \\ ${ }^{\mathrm{b}}$ Departamento de Bioloxía Animal, Bioloxía Vexetal e Ecoloxía, Universidade da Coruña, 15071 A Coruña, Spain
}

Received 26 March 2001; received in revised form 12 November 2001; accepted 21 November 2001

\begin{abstract}
The European shag (Phalacrocorax aristotelis) population at Cíes Islands (the most important breeding area in its southern limit) increased rapidly from 1986 to 1992, and afterwards the population suffered a slight decline. This study analyzed population data obtained from ringing recoveries and reproductive monitoring between 1993 and 1997. The reproductive success was highly variable and associated with adverse weather events. Adult survival rate was very low compared with other colonies, probably due to high accidental capture in gill-nets. In recent years, the fishing effort with gill-nets increased in the study area. Sensitivity analysis of parameters showed that the population is more affected by changes in adult survival than in reproductive success. When dynamic simulations were run with an increase in shag mortality of $5 \%$ above the present level, population extinction occurred in all simulations. In contrast, when a reduction of mortality of 5\% was introduced in the simulations, the population increased in all cases. The main lines of action to study and protect this population should be: (1) ringing schemes to obtain better estimates of survival variability; (2) studies on the interaction of feeding areas and fishing vessels; (3) regulations on gill-netting; and (4) the incorporation of population models as an adaptive management tool to synthesize assessment work and management scenarios. (C) 2002 Elsevier Science Ltd. All rights reserved.
\end{abstract}

Keywords: Phalacrocorax aristotelis; Population dynamics; Reproductive success; Recruitment; Survival

\section{Introduction}

Management and conservation of seabird populations requires an understanding of key population parameters. The effective conservation of seabird populations needs the ability to detect adverse changes as quickly as possible to assess their significance and to determine their possible causes (Croxall and Rothery, 1991). Demographic models, such as capture-markrecapture and Leslie matrix models, are of primary importance to detect population changes (Danchin, 1992). Moreover, analyses of sensitivity to changes in fecundity or survival rates are crucial to design priorities in management plans (Caswell, 1978; Lebreton and Clobert, 1991). Many management strategies are based on demographic parameters estimated in different localities. However, since the mortality risks to seabirds from entanglement in fishing gear, food abundance and weather conditions vary between localities (e.g. Coulson

\footnotetext{
* Corresponding author.

E-mail address: avelando@uvigo.es (A. Velando).
}

and Brazendale, 1968; Furness, 1978; Swann and Ramsay, 1979; Galbraith et al., 1986), the knowledge of the population parameters in each locality is essential in seabird conservation.

European shag (Phalacrocorax aristotelis) distribution is limited to the Western Palearctic, where it breeds from the North Cape to the coasts of Morocco. There are three subspecies. The Atlantic subspecies, $P$. a. aristotelis, is the most abundant and has its southernmost limit along the Atlantic coasts of the Iberian Peninsula. Preliminary analysis of dispersal patterns suggests that this Iberian population is isolated from northern populations (Velando, 1997; Velando and Freire, 1999a). There have been no recoveries from the Iberian Peninsula of shags ringed in France, Britain or Norway, but there are significant movements among these countries (Potts, 1969; Johansen, 1975; Galbraith et al., 1986; Pasquet and Monnat, 1990). In the Iberian Peninsula, distribution of the European shag is quite dispersed and the Cíes Islands are the most important breeding colony, holding c. $42 \%$ of the Iberian population and $2 \%$ of the world population (Velando et al., 1999a). The 
other major colony in the Iberian Peninsula is on the Isle of Ons located $15 \mathrm{~km}$ from Cíes Islands. These two colonies at present account for c. $70 \%$ of Iberian population. Thus, the conservation of shags breeding at Cíes and Ons islands is crucial for preserving the species at its southern limit.

European shags are known to be vulnerable to largescale mortality incidents caused by prolonged adverse weather, dinoflagellate blooms, oil spills, netting and shooting (Coulson et al., 1968; Potts, 1969; Galbraith et al., 1986; Aebischer, 1986; Harris and Wanless, 1996). Demographic data are available for British populations of this species, e.g. at the Farne Islands (Northumberland, England; Potts et al., 1980) and Isle of May (Firth of Forth, Scotland; Aebischer, 1986; Aebischer and Wanless, 1992). There are no data on the population parameters in other localities, except for reproductive success in several British colonies (e.g. Snow, 1960; Olsthoorn and Nelson, 1990; Swann et al., 1994; Walsh and Brindley, 1994) and North Norway (e.g. Barrett et al., 1986; Røv, 1990). The world population is estimated at $<80,000$ breeding pairs (Rose and Scott, 1997), about half of which nested in the British Isles (Lloyd et al., 1991). The monitored British colonies have declined by nearly $43 \%$ from 1987 to 2000 (Lloyd et al., 1991; Mavor et al., 2001). There are no data available on the population trends in other European populations.

The population on the Cies Islands which held c. 400 pairs in 1986 increased to c. 1000 pairs in 1992, indicating an average annual rate of increase of $15 \%$ on the Cíes Islands related to their protection from human activities (Velando et al., 1999a). However, the population suffered a small decrease between 1992 and 2001 (c. 700 pairs). There have been no studies on survival, mortality causes and dispersal in this colony, despite their international importance, and shags were not ringed in this colony until 1993, when this study started. This paper reports the first analysis of population data from Cíes Island obtained from ringing recoveries and reproductive monitoring from 1993 to 1997. In the absence of ringing data, we have used Leslie matrix models in order to assess whether the conditions for shags breeding at Cíes have changed in recent years. Moreover, we have tried to identify the factors driving population changes. Conservation priorities were evaluated using population modelling, allowing the comparison of hypothetical future scenarios (Danchin, 1992).

\section{Methods}

\subsection{Population counts}

The Cíes Islands, a group of three islands (Fig. 1; $\left.42^{\circ} 15^{\prime} \mathrm{N}, 8^{\circ} 53^{\prime} \mathrm{W}\right)$ have a European shag breeding population numbering 1000 pairs which nest in caves

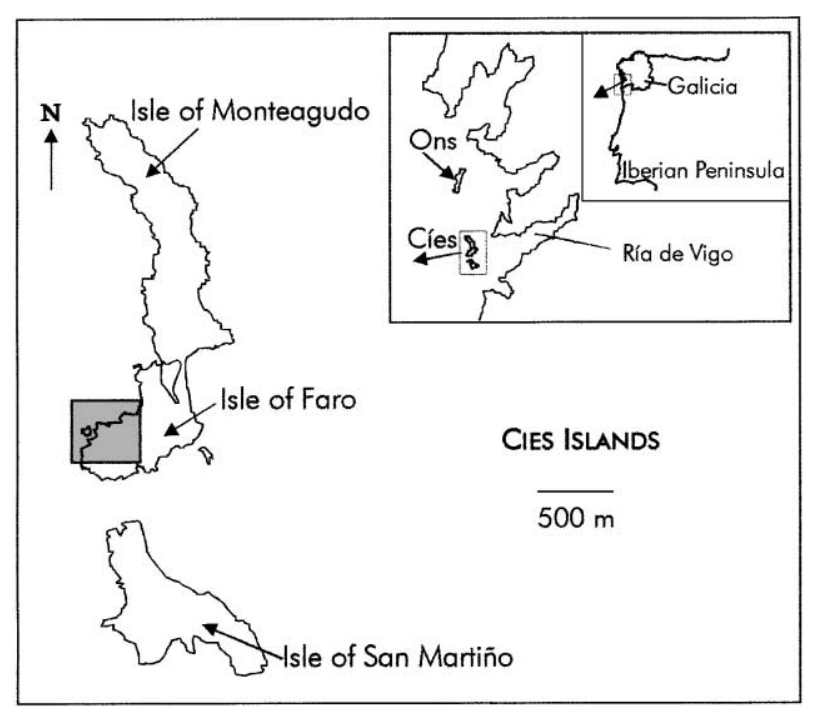

Fig. 1. Cíes Islands (Ría de Vigo), showing the location of the Isle of Faro and the area where shags breed and the field study was carried out. The inset gives the position of the islands in relation to Ría de Vigo, Galicia and the Iberian Peninsula.

formed by granite rocks that fall from the cliffs (Velando and Freire, 2001). Population counts from the land (nests apparently occupied in April-May) were made by five different teams for all the Cíes Islands from 1976 to 1994 (Velando et al., 1999a), and for the Isle of Faro only from 1994 to 2001 by A.V. (Cíes Islands, Fig. 1). The mean annual growth rate, was estimated by $r=\left(\ln N_{t}-\ln N_{0}\right) / t$, where $N_{0}$ is the population size at the outset, $t$ is the time in years, $N_{t}$ is the population size after time $t$ and $r$ is the per capita growth rate of the population. The annual multiplication rate $(\lambda)$ was estimated by $\lambda \mathrm{e}^{r}$.

\subsection{Estimation of population parameters}

Population parameters were estimated in the period 1994-1997. Chick production, as chicks fledged per pair with eggs, was monitored in marked nests on the Isle of Faro during 1994-1997. After hatching, the nests were visited at least every 10 days until fledging (see Velando et al., 1999b). Daytime rainfall was provided by the Instituto Nacional de Meteorología weather station at Vigo airport (Peinador), $20 \mathrm{~km}$ from Cíes Islands. Interannual variability of reproductive success was related to the number of days with rain during May for each season. May was selected because the highest chick mortality occurred in this month during the years under study and it is an important period for the parental care of the chicks (the mean hatching date was 2 May; Velando et al., 1999b). In this month, there are predominantly southerly winds associated with heavy rains (Carballeira et al., 1983). Days with rain were considered to be those having a daytime rainfall $>10 \mathrm{~mm}$. These values have been used because of their adverse 
effect on the sea, affecting light penetration below the surface. This effect probably makes it difficult for shags to capture sandeels (Ammodyidae), the most important prey in Cíes (Velando and Freire, 1999b; Velando et al., 1999b). There is growing evidence that climatic oscillations such as the North Atlantic Oscillation (NAO) are regulating forces on marine and terrestrial ecosystems (Ottersen et al., 2001). In order to test environmental variability over time, we used the Jim Hurrell's NAO index based on the difference of normalized sea level pressure between Lisbon, Portugal and Stykkisholmur/ Reykjavik, Iceland during the winter, December through March (see Hurrell, 1995; http://www.cgd.ucar. $\mathrm{edu} / \sim$ jhurrell/nao.html). The NAO can be useful to assess winter severity: positive values indicate high winter temperature and precipitation (Ottersen et al., 2001).

A total of 1314 chicks and 65 adults in Cíes Islands and Isle of Ons (15 km away) were ringed during the breeding seasons in the 1993-1997 period. Most of the birds were ringed with two rings, a numbered metallic ring provided by the Dirección General de Conservación de la Naturaleza (Ministerio de Medio Ambiente, Spain) and a plastic ring with an individual two-digit combination to facilitate identification from a distance. We analyzed the causes of mortality of ringed recoveries of shags. Because there were no ringing recoveries of shags over time, and in order to investigate temporal trends in the causes of mortality, we examined the recovery circumstances of other ringed diving seabirds in Galicia; in particular, the razorbill (Alca torda) and guillemot (Uria aalge). Changes in the fishing effort over time were analyzed using data available on the Consellería de Pesca, Marisqueo e Acuicultura of Xunta de Galicia (Autonomous Government).

We used resightings of tagged adults to estimate survival. This method depends on the assumption that shags rarely change their breeding area after they have begun to breed, and that returning breeders have the same probability to be identified. We studied the site fidelity in marked nests in order to test these assumptions. Moreover, we have focused only on birds ringed in the Isle of Faro because a higher number of visits were made during the breeding cycle (see e.g. Velando et al., 1999b; Velando, 2000). From capture histories, adult survival rate $\left(\phi_{\mathrm{A}}\right)$ was estimated using CormackJolly-Seber (CJS) models that assume independence of fates and identity of rates among individuals in the population under study (Lebreton et al., 1992). Maximum likelihood estimates of the adult survival and resightings parameters, as well as their asymptotic confidence intervals, were calculated with software SURGE (Clobert et al., 1987; Lebreton et al., 1992). Changes in survival $(\phi)$ and recapture probability $(P)$ rates as a function of time were analysed from saturated models. The choice between different models was made with likelihood ratio tests (Lebreton et al., 1992).
First- and second-year survival ( $\phi_{1}$ and $\phi_{2}$, respectively, see Aebischer, 1986) were estimated from a combination of resighting and recoveries (Aebischer, 1986). The 1994 cohort ringed at Isle of Faro was observed breeding in 1997. Recruitment was estimated as the proportion of 2-year-old birds that nested, corrected by the estimated detection probability $(P)$. We have assumed that all 3-year-old birds were recruited to the population (Potts et al., 1980; Aebischer, 1986). The product $\phi_{1} \phi_{2}$ (first year survival times second year survival) of the 1994 cohort was estimated from the relationship: birds of 1994 cohort surviving to $1997=$ birds hatched in 1994. $\phi_{1} \phi_{2} \phi_{\mathrm{A}}$. Adult survival $\left(\phi_{\mathrm{A}}\right)$ was estimated from capture-recapture (see above) and proportion surviving to 1997 was estimated as the number of birds recorded in 1997 corrected by the recapture probability rate ( $P$, see above). The recapture probability can be higher for adults than for birds ringed as chicks, and this can underestimate $\phi_{1} \phi_{2}$. The specific age survival $\left(\phi_{1}\right.$ and $\left.\phi_{2}\right)$ were estimated from ringing recoveries of shags ringed as chicks and found dead during the first and second year of life using the relationship $\phi_{1} \phi_{2}=\left(1-k a_{1} / N\right)\left(1-k a_{2} /\left(N-k a_{1}\right)\right)$; where $k$ is the inverse reporting rate (number of birds dead/number of birds reported dead); $a_{1}$ is the number of birds reported dead in their first year of life; $a_{2}$ is the number of birds reported dead in their second year of life; and $N$ is the total number of birds ringed as chicks.

\subsection{Population modelling}

We modelled the population dynamics of shags breeding at Cíes Islands using Leslie matrix models (Houllier and Lebreton, 1986; Lebreton and Clobert, 1991; Danchin, 1992) with three age classes (first year, second year and adults). The asymptotic population multiplication rate is obtained as the largest eigenvalue of the Leslie matrix, denoted as $\lambda$. The population is stable when $\lambda$ is equal to 1 , higher values indicate an increasing population and lower values indicate a declining population. Given that survival is independent of sex (Potts et al., 1980), and the males select the nest site and initiate nest-building (Snow, 1963), and there were documented cases of polygyny (about $4 \%$ of males; Potts, 1968; Potts et al., 1980), the model equated nests with breeding males and operated on cohorts of males (Aebischer, 1986; Aebischer and Wanless, 1992). A balanced sex-ratio was assumed in the models. Sex ratio did not differ significantly from the 1:1 expectation in Cíes Islands, (60 males and 67 females; Velando et al., 2002).

We used the models to test whether the demographic parameters estimated in the Cies population fitted the annual rate estimated based on nest counts. Moreover, we tested the sensitivity of annual multiplication rates to changes in fecundity and survival. Finally, we included 
parameter variability in four sets of 100 simulations over 100 year cycles with the actual conditions and with hypothetical future scenarios: an increase or reduction of mortality rate by $5 \%$. In these simulations, fecundity and survival for each year were randomly selected from a normal distribution generated from the average and variance estimates of these parameters (see Caughley and Gunn, 1996). Distributions of adult reproductive success were estimated from environmental variability in rainfall, and assuming similar variability in reproductive success of second-year birds. Variability in survival rates was included from the estimated distribution of adult survival rate. The estimated survival variance represented the sampling variation rather than true interannual variation, but this sampling variability was estimated from data obtained over 4 years. In the absence of a better estimate, we used the sampling variation as a proxy of environmental variability in this parameter. Data are expressed as mean $\pm \mathrm{SE}$.

\section{Results}

\subsection{Population changes}

The European shag population breeding at Cíes Islands showed marked changes defining three different periods (Fig. 2). Between 1976 and 1986 this colony showed an annual increase of 7\%, from 1986 to 1992 the number of breeding pairs showed a rapid increase at an annual rate of $15 \%$, and from 1992 to 2001 the Isle of Faro showed an overall decline at an annual rate of $5 \%$. The peak of breeding pairs was recorded in 1992 with 993 pairs. In 1998, the population crashed attaining only 44 breeding pairs in Isle of Faro, but recovered to 325 pairs in 1999 . The average annual multiplication rate $(\lambda)$ dropped from 1.161 during 1986-1992 to 0.949 during 1992-2001.

\subsection{Number of youngs fledged per pair and environmental variability}

Significant differences among years were found in shag reproductive success on Cíes Islands (1994 to 1997; Median test, $\left.\chi_{3}^{2}=15.73, P<0.001\right)$, largely due to the interannual variability in chick mortality (Velando et al., 1999b). Over the 4 years studied, the productivity was on average 1.46 youngs per pair (Table 1). There were significant differences between age classes in the reproductive success, because second year males reared 0.77 young per pair (Table 1, Mann-Whitney test, $Z=2.73$, df $=263, P<0.01)$. In 1998 , the shags abandoned their clutches during the incubation.

In this colony, chick mortality was related to adverse weather events, especially to the spring rainstorms with southerly winds (Velando et al., 1999b). There was a
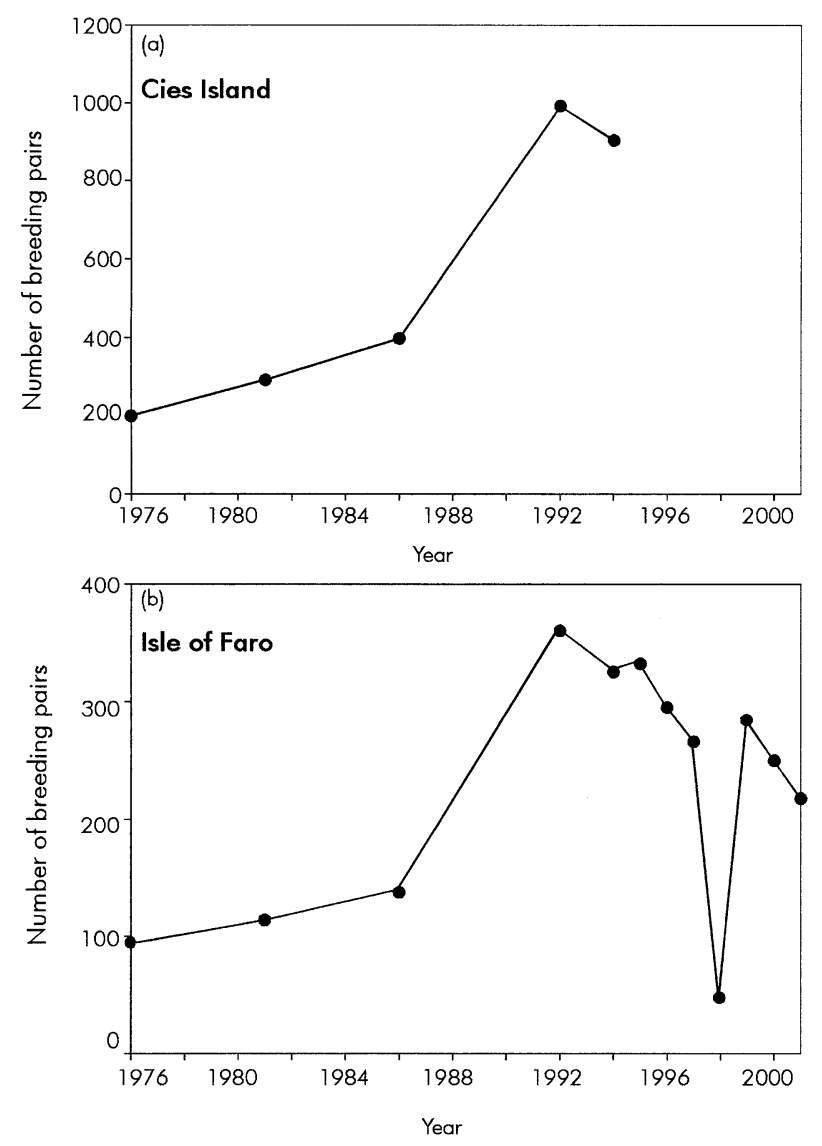

Fig. 2. Changes in the breeding population of the European shag on Cíes Islands (Galicia, northwest Spain) between 1976 and 2001; (a) counts of the whole population of Cíes Islands; (b) counts on Isle of Faro (see Fig. 1).

significant negative relationship between the annual reproductive success and the number of days with rainfall in May (Fig. 3, $r=0.998, \mathrm{df}=3, P=0.001$, reproductive success $=2.08-0.101 \times$ number of days with rainfall in May). Rainfall data in May during the period 1960-1990 was used to assess the potential variability in the number of young fledged per pair. The simulation was restricted to the maximum annual number of young fledged per pair observed (1.86). The mean reproductive success simulated in this period was $1.65 \pm 0.05$ young per pair (Fig. 3). There were no differences in the mean number of days with rainfall in May in the three definite periods (1976-1985: 14.2 $\pm 1.6,1986-1992: 13.0 \pm 1.15$; 1993-2001: $13.5 \pm 1.5$; ANOVA, $F_{2,23}=0.07, P=0.93$ ). There was also no evidence of change in winter severity in these periods comparing Hurrell's winter indexes of NAO (Hurrell's NAO index; 1976-1985: 0.49 \pm 0.57 , 1986-1992: 1.97 $\pm 0.81 ; 1993-2000: 1.07 \pm 0.42$; ANOVA, $\left.F_{2,23}=0.96, P=0.40\right)$.

\subsection{Survival rates and recruitment}

Based on resightings ( $n=52$ birds), we estimated an annual survival rate of breeding adults of $0.72 \pm 0.05$, 
Table 1

Age-specific reproductive success measured as number of chicks fledged per pair of the European shag in Cíes Islands (Galicia, northwest Spain) during a 4-year period

\begin{tabular}{lcll}
\hline \multirow{2}{*}{ Year } & $\begin{array}{l}\text { Nests } \\
\text { studied }\end{array}$ & $\begin{array}{l}\text { Reproductive success } \\
\text { (young/nests) }\end{array}$ \\
\cline { 3 - 4 } & & Mean & SE \\
\hline 1994 & 89 & 1.2 & 0.13 \\
1995 & 93 & 1.83 & 0.14 \\
1996 & 84 & 1.8 & 0.14 \\
1997 & 54 & 1.0 & 0.13 \\
$\begin{array}{l}\text { Annual reproductive } \\
\text { success of adults }\end{array}$ & 320 & 1.46 & 0.21 \\
$\begin{array}{l}\text { Reproductive success } \\
\text { of pairs where the male }\end{array}$ & 15 & 0.77 & 0.23 \\
was a second-year bird & & & \\
\hline
\end{tabular}

corresponding to the mean of the 4 years combined, with a $95 \%$ confidence interval of $0.62-0.82$. Recapture (resighting) probability was estimated at $0.91 \pm 0.04$ with $95 \%$ confidence interval $0.83-0.99$. Survival and recapture probabilities estimates did not vary between years $\left(\phi_{t} P_{t}\right.$ versus $\phi P_{t}: \chi_{3}^{2}=5.2, P>0.1 ; \phi P_{t}$ versus $\phi P$ : $\left.\chi_{3}^{2}=3.0, P>0.1\right)$.

First-year $\left(\phi_{1}\right)$ and second year $\left(\phi_{2}\right)$ survival rates were obtained from recoveries of birds ringed as chicks and sightings of birds which survived until 1997 (see Section 2). We observed 21 birds in 1997 that were ringed as chicks in 1994. From this 1994 cohort hatched on Faro Island $(n=108)$, the estimation of the product $\phi_{1} \phi_{2}$ was $0.30\left(\phi_{1} \phi_{2} \quad 108=(21 / 0.91) /(0.71)\right)$. From 413 birds ringed as chicks between 1993-1995, there were 19 and 4 recoveries of first year and second year birds, respectively. The estimation of the inverse reporting efficiency $(k)$ was 6.29 (see Section 2). Thus, first year survival rate was estimated at 0.43 and second year survival rate at 0.70 .

The rings of 38 second-year old birds were read in 1996-1997. With 81 ringed chicks in 1994-1995 expected to be alive and sampled in their second year, the recruitment rate in their second spring was $47 \%$. I assumed that the remaining shags were waiting until their third year to nest for the first time (Potts et al., 1980).

\subsection{Mortality causes}

There were two main circumstances of ring recovery between 1993 and 1999: birds found dead, and birds caught with fishing nets. There were no differences in the proportion of recoveries from fishing nets between first year and older birds (Fisher's exact test; $P=0.62$ ). Recovery of birds caught on fishing nets accounted for $55 \%$ of the total number of recoveries $(n=79)$. In contrast, in the 1960s five birds were shot and five were
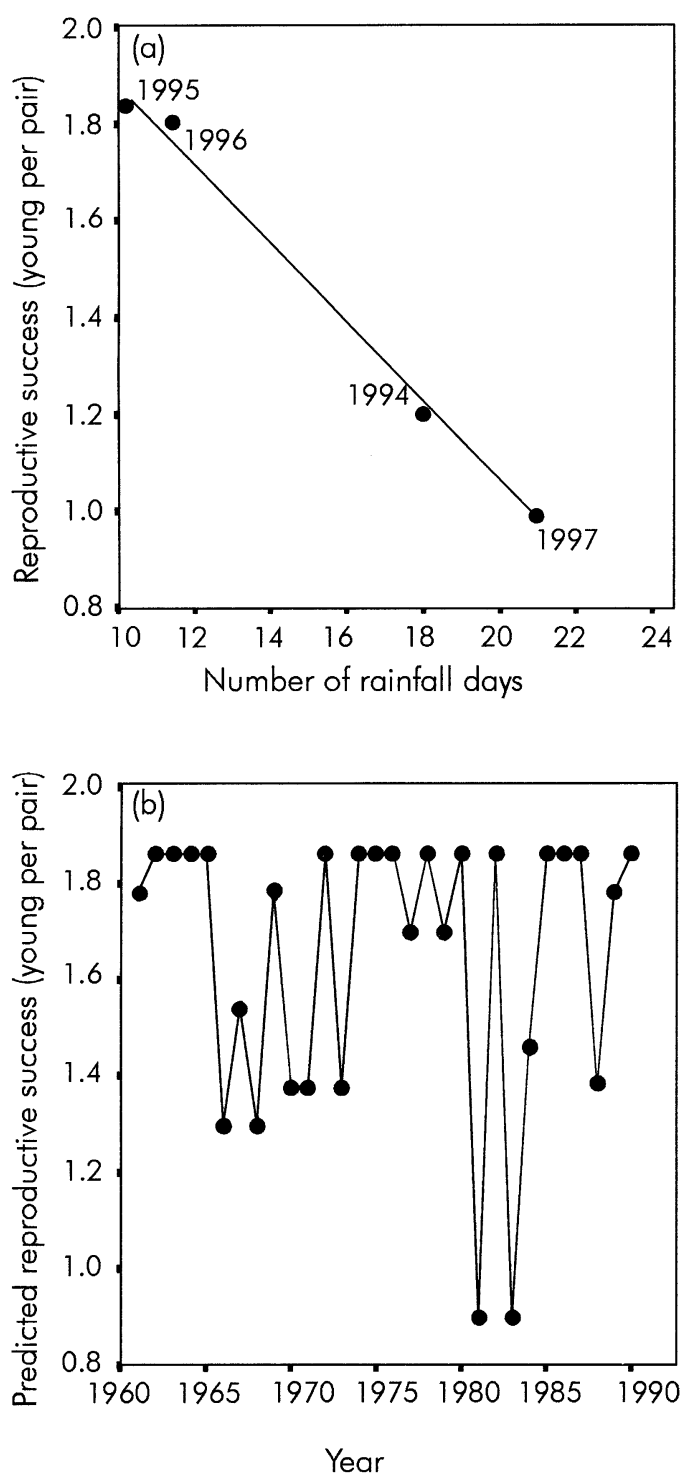

Fig. 3. (a) Relationship between the reproductive success (number of young fledged per pair) of European shag during each breeding season on the Cies Islands (Galicia, northwest Spain) and the number of stormy days in May (stormy days were considered those having daytime rainfall $>10 \mathrm{~mm}$ ). The meteorological data were provided by the weather station of the Instituto Nacional de Meteorología in Vigo at Peinador Airport. (b) Estimation of reproductive success obtained from the number of days with rain in May during the 1960-1990 period (an upper limit was established corresponding to the maximum success observed during the period 1994-1997).

caught by fishing nets reported out of 13 ringing recoveries. There were no ringing recoveries in the 1970 s and 1980s.

In other diving seabirds (razorbills and guillemots), the proportion of recovery circumstances varied markedly with the period studied (Fig. 4). The proportion of alcids recovered from fishing nets increased from the $35 \%$ in the 1980 s to c. $60 \%$ in the 1990 s. The alcid recoveries from shooting accounted for $55 \%$ of the total of recoveries in the 1950-1979 period and declined 


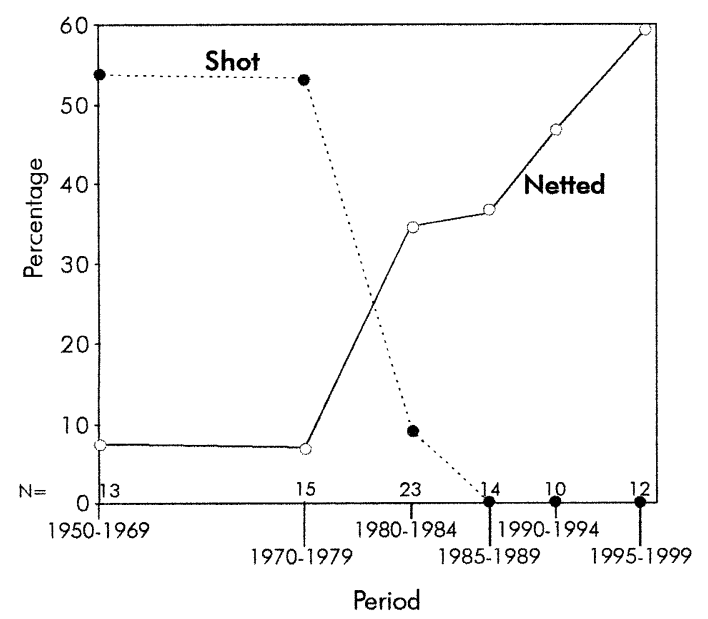

Fig. 4. Changes in the proportion (\%) of reported causes of death of ringed Alcidae (razorbill and guillemot) in Galicia (northwest Spain) over time (solid line, fishing nets; dotted line, shooting). Total numbers of ringing recoveries for each period are given.

during the 1980s. No razorbills or guillemots were reported shot since 1984 .

\subsection{Site fidelity and philopatry}

Based on resightings of 29 adults at marked nests on Faro Island, shags showed a high site fidelity: thus, $61 \%$ of the birds re-nest in the same site as in the previous year, and the remaining birds change the nest within the same area $(<100 \mathrm{~m}$ from the previous nest). A total of 65 rings of birds ringed as chicks were read during the visits to colonies of southern Galicia in 1996-1998. Only one shag hatched in Cíes Islands was seen in another colony (Isle of Ons) and none of the birds ringed in other colonies was recorded breeding at Cíes.

\subsection{Changes on fishing effort}

The fishing effort has increased in the last few decades. The number of gill-net boats in Galicia increased from 1091 to 1856 between 1989 and 1999 (a 70\% increase; Xunta de Galicia, 1990, 2000). In the last few years this trend has grown, for example, the number of gill-net licences in the Ría de Vigo (where the Cíes Islands are located) increased from 480 to 547 between 1995 and 2001(Xunta de Galicia, unpublished data). Moreover, the fishing effort, measured as the total length of nets, showed an annual increase of $10 \%$ between 1980 and 1990 (L. Sampedro and J. Mos, personal communication).

\subsection{Simulation modelling and sensitivity of parameters}

Deterministic Leslie matrix models were used to simulate the dynamics of shags breeding at Cies Islands. Emigration and immigration were ignored. Using the

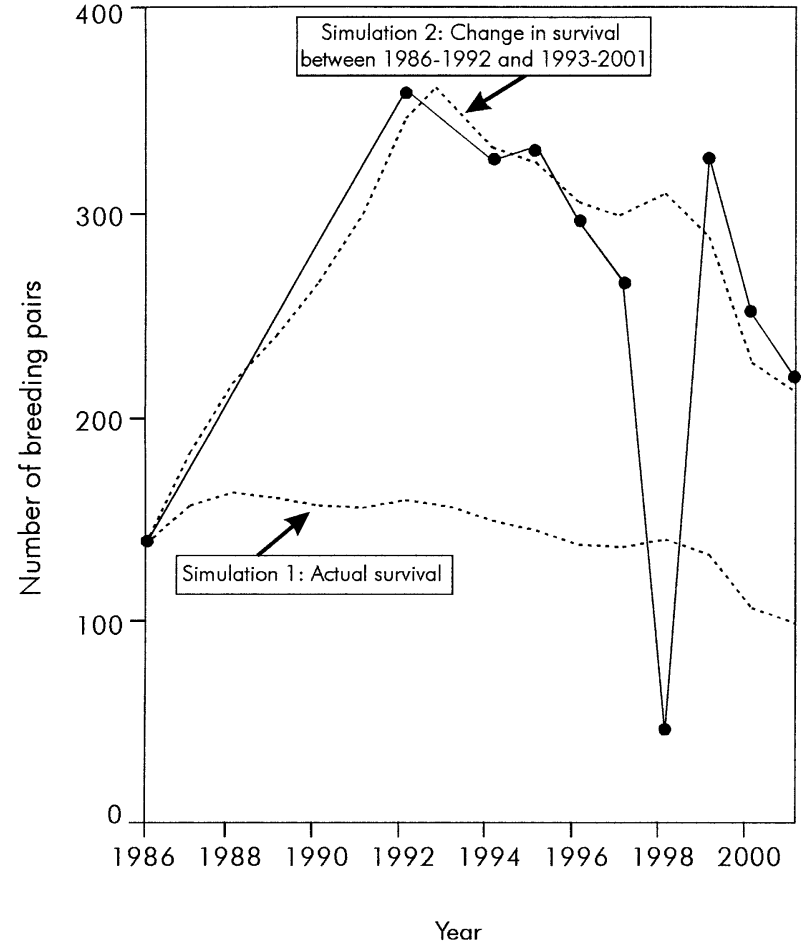

Fig. 5. Results of simulations of the population dynamics of the European shag population breeding at Cíes Islands (Galicia, northwest Spain) between 1986 and 2001, running with the annual reproductive success estimated from annual rainfall (Fig. 3) and no success in 1998. Two simulations were performed: (1) population numbers according to the population parameters estimated in the period 1994-1997; and (2) population numbers according to the population parameters estimated in the period 1994-1997, but with a decrease of $16 \%$ in adult and first year survival in 1992 with respect to the parameters estimated in the period 1994-1997. Solid line and closed circles represent the population size estimated from nest counts.

mean values obtained for population parameters, the asymptotic multiplication rate $(\lambda)$ was 0.975 , close to the average multiplication rate observed from 1992 to 1997 $(\lambda=0.980$; Fig. 5). Simulations of population changes, according to the reproductive success estimated from annual rainfall, showed that population parameters changed between the 1986-1992 and 1993-2001 periods. If the shag population attains an annual rate of increase of $15 \%$, as observed from 1986 to 1992 , adult survival rate must reach a value of 0.84 and first-year survival of 0.49 (Fig. 5). The simulation of the period 1993-2001 with the estimated population parameters is close to the population counts (Fig. 5). The model successfully reproduced the pattern of the recovery from the 1998 crash, indicating that a high proportion of adults did not breed during the crash, but there was no massive adult mortality.

The sensitivity of $\lambda$ to changes in adult survival rate and reproductive success was studied by fixing the remaining parameters in the models (Fig. 6). Changes in adult survival rate had a strong effect on $\lambda$. To attain a stable population $(\lambda=1)$, annual survival rate must 

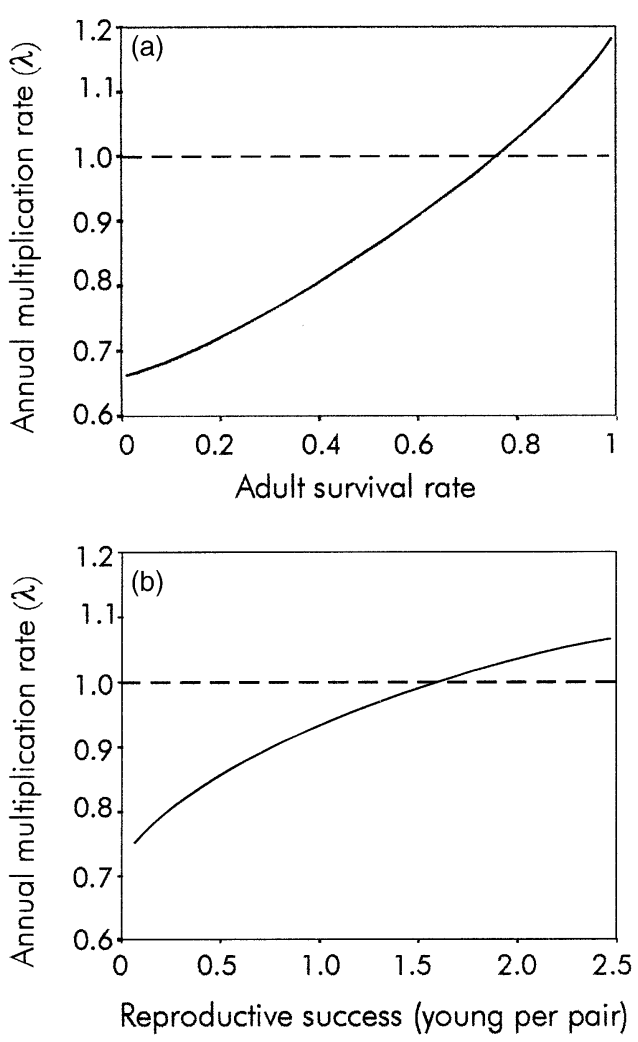

Fig. 6. Sensitivity of $\lambda$ (annual multiplication rate) from the European shag population breeding at Cies Islands (Galicia, northwest Spain) to changes in (a) adult survival rate, and (b) fecundity. Analyses were performed varying one parameter and fixing the remaining parameters. Dotted line shows when the population is stable $(\lambda=1)$.

reach $73.5 \%$. Multiplication rate was more sensitive to adult survival rate than to reproductive success: a reduction by $10 \%$ in adult survival rate reduced $\lambda$ by $9 \%$, but the same percentage of reduction in reproductive success only reduced $\lambda$ by $2 \%$ (Fig. 6).

\subsection{Environmental variability and possible future scenarios}

Three sets of simulations were carried out with population parameters obtained in this study and their variability. Each set of simulations represents the following scenarios: (1) actual conditions, (2) an increase of mortality rate of $5 \%$, and (3) a reduction of mortality rate of $5 \%$. The results from 100 simulations over cycles of 100 years for each set are given in Table 2 .

The set of simulations of actual conditions showed an annual multiplication rate $(\lambda=0.985)$ very close to the observed rate $(\lambda=0.980)$. The population is not at risk of extinction over 100 years with actual conditions but they have a high probability of decline between consecutive years $(57 \%)$. The simulations indicate that a possible slight increase of fishing effort (reduction of adult survival by $5 \%$ ) should involve a high probability of extinction in 100 years $(99 \%)$ with an average time to extinction of 79 years. Nevertheless, a reduction of birds caught in fishing gear (increase of adult survival of $5 \%$ ) might give a population growth of $3 \%$ annually (e.g. Fig. 7).

\section{Discussion}

\subsection{Population parameters of Cíes Islands population}

This study showed that the number of breeding pairs in Cíes Islands increased rapidly from 1986 to 1992, and afterwards this population declined slightly. The differences between annual multiplication rates suggest a change in population parameters in recent decades. Population parameters obtained in this study for shags breeding at Cies Islands and in other localities are summarized in Table 3. Survival rate was lower and reproductive success higher in Cíes Islands than parameters estimated in British colonies. The estimate of the mean adult survival rate of 0.72 is very low compared to the previous estimates for British colonies, and also the upper $95 \%$ confidence limit was lower than average estimates in other colonies. Thus, the estimation of mean annual survival of shags for a 24-year period was 0.88 in Isle of May (Harris et al., 1994).

In comparison to methods based on ringing recoveries, capture-mark-recapture models greatly improve accuracy of the estimates of adult survival rates and therefore allow good estimates based on a relatively small number of birds (Clobert et al., 1987; North, 1987). Nevertheless, these models depend on the assumption that shags rarely change their breeding colony after they recruit. We have found high site fidelity of breeding shags and no marked adult were seen in areas different to that of the previous year. We visited at least three times per year all the breeding areas of Cies Islands (>1.5 km of coastline) and Isle of Ons (15 km away) and the marked adults were always seen within $100 \mathrm{~m}$ of the nest used in previous years. Aebischer et al. (1995) reported similar site and area fidelity in the east coast of Britain. Therefore, this assumption seems to be realistic in the case of shags breeding at Cies Islands. Some studies have found evidence of annual differences in survival of adult shags (Coulson et al., 1968; Potts et al., 1980) We did not find annual differences in survival rates but the sample size in our study was not adequate to detect such variation. Harris et al. (1994) showed no differences in annual survival rate of adult shags over a 24-year period. Nevertheless, more resightings would be needed to assess annual variability and more accurate survival rates in Cíes Islands.

The confidence interval of survival rate indicates a high mortality in the Cíes Islands compared with other populations. Data from ringing recoveries indicated that fishing nets are the main cause of reported unnatural 
Table 2

Results from three sets of 100 simulations, each run over 100 cycles of an European shag population breeding at Cíes Islands (Galicia, northwest Spain)

\begin{tabular}{|c|c|c|c|c|c|}
\hline \multirow{2}{*}{$\begin{array}{l}\text { SETS (100 simulation over } \\
100 \text { year-cycles) }\end{array}$} & \multicolumn{3}{|c|}{ Annual multiplication rate $(\lambda)$} & \multirow{2}{*}{$\begin{array}{l}\text { Annual probability } \\
\text { of decrease }(\%)\end{array}$} & \multirow{2}{*}{$\begin{array}{l}\text { Probability of extinction } \\
\text { in } 100 \text { years }(\%)\end{array}$} \\
\hline & Mean & $\mathrm{SD}$ & Range & & \\
\hline Actual conditions & 0.985 & 0.08 & $0.63-1.38$ & 57 & 0 \\
\hline Increase by $5 \%$ in the mortality rate & 0.901 & 0.08 & $0.60-0.84$ & 84 & 99 \\
\hline Reduction by $5 \%$ in the mortality rate & 1.032 & 0.08 & $0.71-0.38$ & 38 & 0 \\
\hline
\end{tabular}

All the simulations include variability in reproductive success and survival rates by selection of these parameters from their estimated statistical distributions. The sets of simulations include: actual conditions, an increase of $5 \%$ in the mortality rate, a reduction of $5 \%$ in the mortality rate. Mortality by fishing nets was assumed similar in all age classes. Annual probability of decrease, as the percentage of years with a decrease of population size, and probability of extinction, as the percentage of simulations where the population disappeared, are given for each set of simulations.
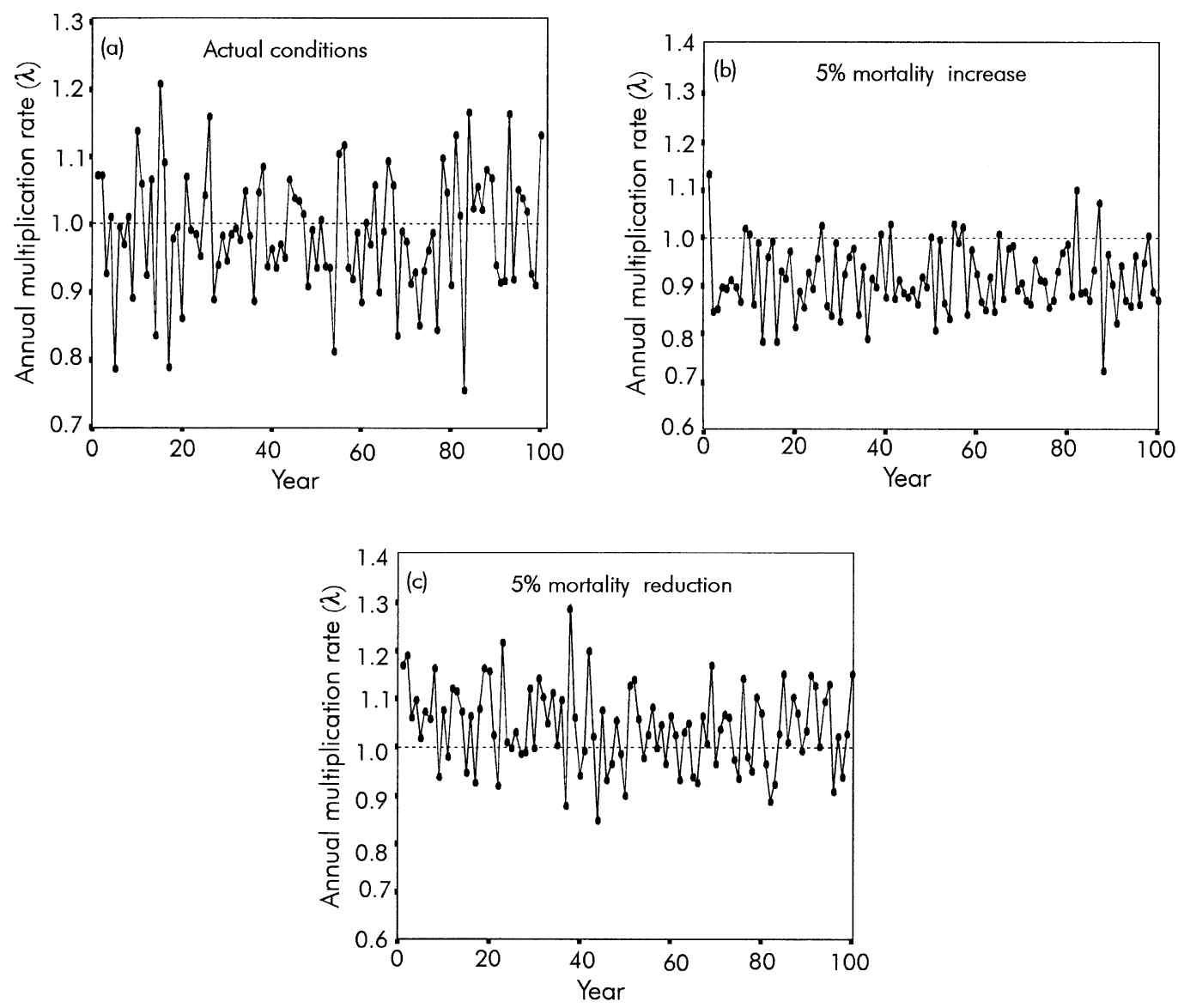

Fig. 7. One example of each set of 100 simulations of asymptotic annual multiplication rate of the European Shag population breeding at Cies Islands (Galicia, northwest Spain) running with parameter variability during a 100-year cycle according to (a) estimated actual conditions, (b) an increase of $5 \%$ in the mortality rate, (c) a reduction of $5 \%$ in the mortality rate. The dotted line represents a stable population $(\lambda=1)$.

mortality among shags and are responsible of at least $55 \%$ of the ringing recoveries of shags breeding on the Galician coast. The shag mortality rate caused by fishing gear could be greater because most of the shags found dead on beaches showed their neck feathers dishevelled, which probably indicates that they were caught in fishing nets. Estimates obtained from interviews with local fishermen indicate that a total of around 4000 shags and cormorants (Phalacrocorax carbo) are probably caught annually by single and composite gill-nets in Galicia, (Arcos, Velando and Mouriño, personal communication). Thus, the high mortality in fishing devices could be responsible for the low adult survival rate observed in Cíes Island.

The Leslie matrix models should be applied only in geographically closed populations or in populations with balanced movements (emigration and immigration). Aebischer (1995) showed that $95 \%$ of shags are 
Table 3

Population parameters of different European shag populations (Sources: Isle of May: Aebischer, 1986; Farne Islands: Potts et al., 1980; Cíes Islands: this study)

\begin{tabular}{llllll}
\hline & \multicolumn{2}{l}{ Survival } & & & \multicolumn{1}{c}{$\begin{array}{c}\text { Fecundity } \\
\text { (young/pair) }\end{array}$} \\
\cline { 2 - 5 } & Adult & 2-year old & 1-year old & $\begin{array}{c}\text { Recruitment of } \\
\text { 2-year old (\%) }\end{array}$ \\
\hline May & $0.85(0.83-0.87)$ & 0.74 & 0.50 & 1.12 & 53 \\
Farne & $0.83(0.81-0.85)$ & 0.75 & 0.51 & 1.03 & 65 \\
Cíes & $0.72(0.62-0.82)$ & 0.70 & 0.42 & 1.45 & 47 \\
\hline
\end{tabular}

Confidence intervals for adult survival are given between parentheses

recruited within a radius of $<8 \mathrm{~km}$ from the natal colony in eastern Britain. European shags also showed a high philopatry in Cíes Islands, thus, Leslie matrix models may be applied to this shag population, but further investigations on shags movements are required to estimate large movements (Coulson and Nève de Mévergnies, 1992). The results of simulation models should be treated with caution because the data used to estimate some parameters are not completely accurate. First year survival rate was estimated for only one cohort, but it has been showed that this parameter is variable from year to year (Aebischer, 1986). Our estimates of annual multiplication rates ignore this source of variation. In addition, it has been shown that male shags recruit earlier than females (Potts et al., 1980; Aebischer, 1986). Thus, our estimate of recruitment based on both sexes combined could underestimate male recruitment. Nevertheless, this biased estimate is not a major weakness given that, for example, in the extreme case where $100 \%$ male shags recruit in their second year, the annual multiplication rate would increase by only $1 \%(\lambda=0.988)$, with similar conclusions. The correspondence between the counts and population size estimated from modelling (Fig. 5) during the period following (1998-2001) the period used to estimate the parameters (1994-1997), avoiding circularity (Coulson et al., 2001), suggests a realistic accuracy of the parameter estimates. Moreover, simulation modelling indicated that the population crash in 1998 was due to the fact that some adults that had bred in previous years did not breed this year, a common feature of shag biology reported in other colonies (Aebischer and Wanless 1992).

\subsection{Diagnostic of population changes over time}

Deterministic and dynamic simulations with the parameters estimated showed that the population is close to being stable but with a slight tendency to decline. This contrasts with the rapid increase from 1986 to 1992 , probably related to the fact that these islands were declared a Natural Park in 1980 and since 1984 have been managed by the Autonomous Government (Xunta de Galicia) when the Wildlife Service was star- ted. Moreover, the ban on hunting from boats in 1980, and the enforcement of this ban in the 1980s has effectively eliminated the killing of shags by shooting (Velando et al., 1999a). In fact, no ringing recoveries from shooting of other seabirds (Alcidae) have been reported since 1984 (see Fig. 4). This combination of a high recruitment rate due to habitat protection and a reduction in adult mortality can explain the rapid increase in this period.

At present, conditions seem to have changed and this could be due to various causes. Density-dependent processes could stabilize population size (Potts et al., 1980; Lebreton and Clobert, 1991). Nevertheless, fecundity reported during this period (1.00-1.83 chicks per pair) was very high compared with other studies (Table 3 ). During a period of population increase on the Isle of May, the highest value reported was 1.43 young fledged per pair (Aebischer, 1986) and on the Farne Islands the highest value recorded was 1.15 young per pair. Thus, conditions on Cíes seem to be good for breeding shags. Nest-site quality can also regulate the breeding pairs by reducing the recruitment (Potts et al., 1980; Duffy, 1983; Porter and Coulson, 1987). The density of breeding pairs in Cíes Islands is very low compared to British colonies (Velando and Freire, 2001), and there are many areas with apparently good breeding sites that are not used at the moment (Velando and Freire, 1999a). There were no data on recruitment prior to this study making it difficult to assess the effects of potential recruitment changes in population dynamics. Moreover, environmental changes cannot explain the observed variation in breeding numbers at Cíes Islands. Nevertheless, increased fishing effort in recent decades (see Fig. 4), and consequent changes in survival rates, seems to be a major factor responsible for the decline in the annual multiplication rate observed.

\subsection{Implications for conservation and management strategy}

This study showed that population modelling is a useful tool for effective conservation, by (1) detecting adverse changes, (2) assessing the significance of these, and (3) determining their possible causes. Population 
modelling in a conservation strategy should be a dynamic process, where the data are collected continuously and added to the models and their conclusions reassessed, and if necessary strategies altered (Coulson et al., 2001). The actual management strategy for the population of shags breeding at Cíes Islands is restricted to the protection of shags in the colony during their breeding cycle. Thus, traditional practices have been stopped, such as the stealing of eggs and capture of chicks for human consumption, and there has been a reduction in human disturbance. This management strategy has probably improved shag fecundity. Nevertheless, the results of the simulation modelling suggested changes in the population dynamics in recent decades. Thus, the population declined slightly in the 1990s. The management strategy should change when the conditions change.

After the diagnosis of the population decline, the next crucial step in a conservation strategy is the assessment of the causes of this decline (Caughley, 1994). The simulation models used in the present study suggest that changes in mortality could be responsible for the present trend. As stated above, accidental capture in composite gill-nets seems to be of great importance for the population. The Galician coast supports a high fishing effort (Freire and García-Allut, 2000), and > 1800 commercial vessels are using gill-nets. The present fishery management regulations are directed to the direct protection of the resources (closed seasons, minimum sizes), but not to the fishing techniques. Also, illegal and unregulated fisheries use gill-nets in shallow waters during the whole year (Freire et al., 2002). Population simulations showed that the survival affects the population changes more strongly than reproductive success (Figs. 6 and 7).

Fishing effort caused by single and composite gill-nets in Galician coasts has grown dramatically during the 1990s. Thus, the number of gill-net vessels in Galicia increased by $70 \%$. The increase of fishing nests is due mainly to a restructuring of the fleet, where numerous long-liners and trawlers were transformed in gill- and tangle-netters. These changes were due to two main reasons: (1) over-exploitation of demersal stocks in the continental shelf that are the target of long-liners and trawlers, whereas gill-nets exploit coastal resources that supported a much lower fishing effort at the start of the restructuring period (although at the present this effort is very high; Freire and García-Allut, 2000); (2) savings in the costs of exploitation of the fleet: trawling and long-lines need large vessels and a relatively large number of fishers involved in fishing operations, whereas gill-nets can be operated from small vessels $(<10-15 \mathrm{~m})$ with usually $2-3$ men.

In conclusion, this study highlights the vulnerability of the European shag population breeding at Cíes Islands. This study suggests that the main lines of action to protect this population should be: (1) protection of the important shag feeding areas; and (2) regulations on the gill-net fishery, to limit their use in the shag feeding areas and to control the compliance of this regulation. Moreover the diagnostic management strategy should be centred on two main topics: (1) develop ringing schemes to obtain better estimates of age-specific survival and its annual variability; and (2) studies on feeding areas used by shags and the interaction with fishing vessels. As ecological systems are dynamic, research is required to estimate how changes from one regulating factor to another influence the distribution of vital rates and population growth.

\section{Acknowledgements}

We thank Francisco Docampo, Alvaro Pomares, Emilio Martinez, David Taín and Agustín Alcalde for help in ringing European shags in Cíes and Ons Islands. We thank Ministerio de Medio Ambiente and Pablo Sierra for providing recovery information. We thank also Drs. J.E. Ortega-Ruano, J. Dominguez, L. Sampedro, B.N.K. Davis, J. Nichols and one anonymous referee for helpful comments on earlier drafts. This study was partially supported by the Servicio de Medio Ambiente (Xunta de Galicia).

\section{References}

Aebischer, N.J., 1986. Retrospective investigation of an ecological disaster in the shag, Phalacrocorax aristotelis: a general method based on long term marking. Journal of Animal Ecology 55, 613-619.

Aebischer, N.J., 1995. Philopatry and colony fidelity of Shags Phalacrocorax aristotelis on the east coast of Britain. Ibis 137, 11-28.

Aebischer, N.J., Wanless, S., 1992. Relationships between colony size and enviromental conditions for Shags Phalacrocorax aristotelis on the Isle of May, Scotland. Bird Study 39, 43-52.

Aebischer, N.J., Potts, G.R., Coulson, J.C., 1995. Site and mate fidelity of Shags Phalacrocorax aristotelis at two British colonies. Ibis 137, 19-28.

Barrett, R.T., Strann, K.B., Vader, W., 1986. Notes on the eggs and chicks of North Norway Shags Phalacrocorax aristotelis. Seabird 9, 73-83.

Carballeira, A., Devesa, C., Retuerto, R., Santillan, E., Ucieda, F., 1983. Bioclimatología de Galicia. Fundación Pedro Barrie de la Maza, A Coruña (in Spanish).

Caswell, H., 1978. A general formula for sensitivity of population growth rate to changes in life history parameters. Theoretical Population Biology 14, 215-230.

Caughley, G., 1994. Direction in conservation biology. Journal of Animal Ecology 63, 215-244.

Caughley, G., Gunn, A., 1996. Conservation biology in theory and practice. Blackwell Science, Cambridge.

Clobert, J., Lebreton, J.D., Allainé, D., 1987. A general approach to survival rate estimation by recaptures or resightings of marked birds. Ardea 75, 133-142.

Coulson, J.C., Brezandale, M.G., 1968. Movements of cormorants ringed in the British Isles and evidence of colony-specific dispersal. British Birds 61, 1-21. 
Coulson, J.C., Nève de Mévergnies, G., 1992. Where do young Kittiwakes Rissa tridactyla breed, philopatry or dispersal? Ardea 80, 187-197.

Coulson, J.C., Potts, G.R., Deans, I.R., Fraser, S.M., 1968. Exceptional mortality of shags and other seabirds caused by paralytic shellfish poison. British Birds 61, 381-404.

Coulson, T., Mace, G.C., Hudson, E., Possingham, H., 2001. The use and abuse of population viability analysis. Trends in Ecology and Evolution 16, 219-221.

Croxall, J.P., Rothery, P., 1991. Population regulation of seabirds: implications of their demography for conservation. In: Perrins, C.M., Lebreton, J.D., Hirons, G.M. (Eds.), Bird Population Studies: Relevance to Conservation and Management. Oxford University Press, Oxford, pp. 272-296.

Danchin, E., 1992. Modelling seabird population and implications for management introduction. Ardea 80, 157-160.

Duffy, D.C., 1983. Competition for nesting space among Peruvian Guano birds. Auk 100, 680-688.

Freire, J., García-Allut, A., 2000. Socioeconomical and biological causes of management failures in European artisanal fisheries: the case of Galicia (NW Spain). Marine Policy 24, 375-384.

Freire, J., Bernárdez, C., Corgos, A., Fernández, L., GonzálezGurriarán, E., Sampedro, M.P., Verísimo, P., 2002. Management strategies for sustainable invertebrate fisheries in coastal ecosystems of Galicia (NW Spain). Aquatic Ecology, 36, 41-50.

Furness, R.W., 1978. Migrations and survival rates of Great Skuas ringed in Scotland. Bird Study 25, 229-238.

Galbraith, H., Baillie, R., Furness, R.W., Russell, S., 1986. Regional variations in the dispersal of Shags Phalacrocorax aristotelis in northern Europe. Ornis Scandinavica 17, 68-74.

Harris, M.P., Wanless, S., 1996. Differential responses of Guillemot Uria aalge and Shag Phalacrocorax aritotelis to a late winter wreck. Bird Study 43, 220-230.

Harris, M.P, Buckland, S.T., Russell, S.M., Wanless, S., 1994. Yearand age-related variation in the survival of adult European Shags over a 24-year period. Condor 96, 600-605.

Houllier, F., Lebreton, J.D., 1986. A renewal-equation approach to the dynamics of stage-grouped populations. Mathematical Biosciences 79, 185-197.

Hurrell, J.W., 1995. Decadal trends in the North Atlantic Oscillation: regional temperatures and precipitations. Science 269, 676-679.

Johansen, O., 1975. The relation between breeding grounds and wintering grounds in Norway as shown by ringing recoveries. Sterna 14, $1-21$.

Lebreton, D.J., Clobert, J., 1991. Bird population dynamics. Management and conservation: the role of mathematical modelling. In: Perrins, C.M., Lebreton, J.D., Hirons, G.M. (Eds.), Bird Population Studies: Relevance to Conservation and Management. Oxford University Press, Oxford, pp. 105-125.

Lebreton, J.D., Burnhan, K.P., Clobert, J., Anderson, D.R., 1992. Modelling survival and testing biological hypotheses using marked animals: a unified approach with case studies. Ecological Monographs $62,67-118$.

Lloyd, C.S., Tasker, M.L., Partridge, K.E., 1991. The Status of Seabirds in Britain and Ireland. T.A. \& A.D. Poyser, London.

Mavor, R.A., Pickerell, G., Heubeck, M., Thompson, K.R., 2001. Seabird numbers and breeding success in Britain and Ireland, 2000, (UK Nature Conservation, No. 25). Joint Nature Conservation Committee, Peterborough.

North, Ph. M (Ed.), 1987. Ringing recovery analytical methods. Acta Orn. 23, 1-175.
Olsthoorn, J.C.M., Nelson, J.B., 1990. The availability of breeding sites for some British seabirds. Bird Study 37, 145-164.

Ottersen, G., Planque, B., Belgrano, A., Post, E., Reid, P., Stenseth, N.C., 2001. Ecological effects of the North Atlantic Oscillation. Oecologia 128, 1-14.

Pasquet, E., Monnat, J.Y., 1990. Dispersion géographique des Cormorans huppés juvéniles de la mer Celtique. L'Oiseau et R.F.O. 60 , 94-109.

Porter, J.M., Coulson, J.C., 1987. Long-term changes in recruitment to the breeding group, and the quality of recruits at a kittiwake Rissa tridactyla colony. Journal of Animal Ecology 56, 765-790.

Potts, G.R., 1968. Success of eggs of the shag on the Farne Islands, Northumberland, in relation to their content of Dieldrin and pp'DDE. Nature 217, 1282-1284.

Potts, G.R., 1969. The influence of eruptive movements, age, population size and other factors on the survival of the shag (Phalacrocorax aristotelis). Journal of Animal Ecology 38, 53-102.

Potts, G.R., Coulson, J.C., Deans, I.R., 1980. Population dynamics and breeding success of the shag, Phalacrocorax aristotelis, on the Farne Islands, Northumberland. Journal of Animal Ecology 49, 465-484.

Rose, P.M., Scott, D.A., 1997. Waterfowl population estimates. Wetlands International Publication 44, 1-106.

Røv, N., 1990. Population studies of shags Phalacrocorax aristotelis in Norway. NINA Forskningrapport 7, 1-28.

Snow, B., 1960. The breeding biology of the shag Phalacrocorax aristotelis on the island of Lundy. Bristol Channel. Ibis 102, 554-575.

Swann, R.L., Ramsay, A.D.K., 1979. An analysis of Shag recoveries from north west Scotland. Ringing and Migration 2, 137-143.

Swann, R.L., Aiton, D.G., Carrunthers, J., Graham, R.J., Ramsay, A.D.K., 1994. An analysis of Shag Phalacrocorax aristotelis ring recovery and breeding success data during a period of population change on the Isle of Canna. Seabird 16, 50-56.

Velando, A., 1997. Ecología y Comportamiento del Cormorán Moñudo Phalacrocorax aristotelis en las Islas Cíes y Ons. PhD dissertation, University of Vigo, Vigo.

Velando, A., 2000. The importance of the hatching date on dominance of young shags. Animal Behaviour 60, 181-185.

Velando, A., Freire, J., 1999a. Coloniabilidad y conservación de aves marinas: El caso del cormorán moñudo. Etologia 7, 55-62.

Velando, A., Freire, J., 1999b. Intercolony and seasonal differences in the breeding diet of European shags on the Galician coast (NW Spain). Marine Ecology Progress Series 188, 225-236.

Velando, A., Freire, J., 2001. How general is the central-periphery distribution among seabirds? Nest spatial pattern in the European Shag. Condor 103, 544-554.

Velando, A., Docampo, F., Alvarez, D., 1999a. Status of European shag population on the Atlantic coast of Iberian Peninsula. Atlantic Seabird 1, 105-114.

Velando, A., Ortega-Ruano, J.E., Freire, J., 1999b. Chick mortality in European shag Stictocarbo aristotelis related to food limitations during adverse weather events. Ardea 87, 51-59.

Velando, A., Graves, J., Ortega-Ruano, J.E., 2002. Sex ratio in relation to timing of breeding, and laying sequence in a dimorphic seabird. Ibis 144, 9-17.

Walsh, P., Brindley, E., 1994. Great Britain and Ireland seabird breeding success in 1993. The Seabird Group Newsletter 68, 3-6.

Xunta de Galicia, 1990. Censo da frota pesqueira de Galicia. Consellería de Pesca, Santiago de Compostela.

Xunta de Galicia. 2000. A frota costeira de Galicia. Consellería de Pesca, Marisqueo e Acuicultura, Santiago de Compostela. Available: http://www.xunta.es/conselle/pe/flotacosteira.htm. 